\title{
Reflective writing: Experience of first professional medical students with Attitude ethics and communication module
}

\author{
Tikare, S.N. ${ }^{1}$, Dhundasi, S.A. ${ }^{2}$
}

\begin{abstract}
:
Introduction: Teaching and learning of medical ethics, communication skills, leadership and team building skills had not received due attention in the Indian medical curriculum that we had till recently. The Medical Council of India/ Board of Governors emphasized the need for development of appropriate attitude and communication skills among the students. Thus, Attitude ethics and communication (AETCOM) module was envisaged for all phases of undergraduate medical program. Our study analyzed the response of the students to AETCOM module and their reflective writings.

Materials and Methods: The study was conducted among students of 2017-18 and 2019-20 batch at a medical college in the state of Karnataka, India. It examines the response of first professional year students to AETCOM module sessions. The medical students submitted the reflective writing/ narratives, following a series of sessions on the first AETCOM module topic. The study was approved by the Institutional ethics committee.

Results: The content of the narratives were analysed for the values, attitudes, roles and responsibilities of a doctor as perceived by the students using predetermined codes. A comparative analysis of the two groups yielded very usable information which could improvise the teaching-learning and assessment methods in practical implementation of AETCOM modules.

Discussion: Narratives and reflective writing are important tools for learning attitudinal and ethical issues. It is a metacognitive process that creates greater understanding of self and situations and prepares for an informed future action. The MCl/ BOG envisaged AETCOM module will help students acquire necessary competence in the attitudinal, ethical and communication domains.
\end{abstract}

Key words: AETCOM module, reflective writing, CBME curriculum, medical ethics, humanities in medicine, medical teaching.

\section{Introduction:}

The Competency based medical education (CBME) has been rolled out across all the medical colleges of India in the academic year 2019-20. The preparations for the same were underway since long. The Medical Council of India/ Board of Governors (MCl/ BOG) had prepared the vision 2015 document, to provide a road map in attaining global standards in undergraduate medical education program. (Medical Council of India Vision 2015) Along with the requisite knowledge and psychomotor skills, it emphasized the need for development of appropriate attitude and communication

${ }^{1}$ Faculty, Department of Medical Education, Al Ameen Medical College, Vijayapur, India.

${ }^{2}$ Dean and Professor, Department of Physiology, Al

Ameen Medical College, Vijayapur, India.

Corresponding Author: Dr.Swati N. Tikare

Professor, Department of Physiology, Al Ameen medical college, Vijayapur 586103 Karnataka, India e-mailswatimalini@gmail.com skills among the students. The $\mathrm{MCl}$ envisaged the Attitude Ethics and Communication (AETCOM) module as a guideline to incorporate Attitudes, Medical ethics and Communication in regular curriculum in all the phases of undergraduate program (Attitude, ethics \& communication competencies for the Indian medical graduate, 2018). Numerous Faculty development programs were conducted through $\mathrm{MCl}$ nodal centers to disseminate the information to the faculty members. Subsequently after five years of meticulous planning, deliberation, preparation and brainstorming the CBME curriculum was introduced to phase one MBBS students of 2019-20 batch. The novel changes introduced to the first professional year students included Foundation course, Early clinical exposure, Horizontal and Vertical Integration, Selfdirected learning, Skill certifications and AETCOM module. (Competency based

DOI: http://doi.org/10.4038/seajme.v15i1.260

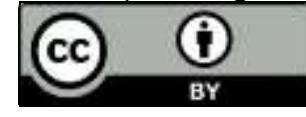

41

(C) SEAJME. This is an Open Access article distributed under the terms of the Creative Commons Attribution License (http://creativecommons.org/licenses/by/4.0/), which permits unrestricted use, distribution, and reproduction in any medium, provided the original author and source are credited 
undergraduate curriculum for the Indian medical graduate, 2019)

The MCl/BOG introduced a structured longitudinal programme on attitude, communication and ethics to the students under the CBME curriculum. The two major aspects of teaching the above domains include explicit teaching of cognitive base and stage appropriate opportunities for experiential learning and reflection throughout the curriculum.

Reflective writing is an important tool for learning attitudinal and ethical issues. It is a metacognitive process that creates greater understanding of self and situations and prepares for an informed future action. (Sandars, 2009). As per Boyd and Fales reflection is 'The process of internally examining \& exploring an issue of concern, triggered by an experience, which creates \& clarifies meaning in terms of self, \& which results in a changed conceptual perspective'. (Boyd et al 1983)

A study by Novack opined "To restore humanism to medical care, medical education needs to espouse the goal of creating physician -healers". Self-awareness skill was identified as important and also its teaching to the students deemed essential. (Novack et al., 1999). Evaluation is a vital component of any educational program which critically examines the program. It involves collecting and analysing information about a program's activities, characteristics, and outcomes. Its purpose is to make judgments about a program, to improve its effectiveness, and/or to inform programming decisions (Patton, 1987). Thus, we wanted to analyse the AETCOM module, to improvise its implementation and maximise the benefits to the students. The objective of our study was to do Qualitative analysis of the reflective writings written by $1^{\text {st }}$ MBBS students of two groups of our institution following sessions on AETCOM module 1, of first Professional year. In addition, we intended to analyze the pattern of responses during the pilot study on Group I students of 2017-18 batch, and propose suggestions for teaching learning sessions to improve the conduct of AETCOM sessions. Subsequently for the group II students these suggestions were implemented along with new inputs from the $\mathrm{MCl} / \mathrm{BOG}$ and again analyzed the pattern of responses from the students of CBME batch.

\section{Material and Methods}

This is a cross sectional study conducted at a private medical college in Karnataka State, India. The present study includes a pilot study conducted on first professional medical students of 2017-18 batch (Group I) and subsequently on the first professional medical students of CBME batch of 2019-20 (Group II). Prior to the study the students were oriented regarding the AETCOM module. We conducted different sessions for students of both the groups on the topic of first AETCOM module1.1; What it means to be a doctor? The inclusion criteria for the study were full attendance and participation in all the sessions scheduled for the particular batch for the delivery of the AETCOM module and response in the form of submitting their reflective writings. Students who missed one or more sessions were not included in the study.

During the study on group I students, the AETCOM module was published and training of faculty for the same was underway but it was not yet formally introduced in the curriculum. For the group I students, the following sessions were conducted under the AETCOM Module

\subsection{What it means to be a doctor?}

i. A Large group interactive session was conducted on the Attributes of a doctor and Professionalism

ii. Cine-education: Clipping of a Hindi movie "Anand" which shows a fresh medical graduate's encounter with real patients and the diverse socioeconomic conditions that impact the disease and the patients. The doctor is shown to have the habit of dairy or journal writing which makes him reflect and ponder on the happenings. It also tries to draw a comparison of an ethical doctor with another doctor with lesser professional values.

iii. Small Group Discussion on "What it means to be a doctor?" Roles and Responsibilities.

For Group II students of 2019-20 CBME batch, in addition to the above sessions the following sessions were conducted

i. A facilitated panel discussion including an Intern, Postgraduate, specialty doctors and general practioners at various stages of their careers and diverse places of work was conducted. They shared their experiences and also answered queries from the students. 
ii. Self-directed learning was encouraged between the sessions.

iii. Students were taken for a visit to a community medical centre in groups to observe the working of the medical officer in the outpatient department.

iv. A component of experiential learning was introduced by giving Group work (six groups of 25 students each) to the students to plan and enact role plays on the following six attributes of a doctor; Integrity, Confidentiality, Good Communicator, Justice to all, Professionalism and Empathy. An internee was assigned to each group as a facilitator.

v. An elaborate large group interactive session was conducted on the purpose, usefulness and technique of writing Narratives \& Reflective writing with hands on experience.

The sessions four and five, role plays by students and teaching the importance and method of writing reflections were in addition to the sessions recommended in the AETCOM module booklet. The students of both the groups were given one week's time after the last session of AETCOM for the submission. The group I students consenting for the study were requested to submit their reflective writings. For group II students of CBME batch 2019-20 reflective writing and recording it in their logbook was compulsory as per new CBME curriculum. A written informed consent was obtained from all the students of both the groups who accepted to be part of the study. The study was approved by the Institutional ethics committee for both the groups.

The pattern of students' responses was analyzed for the differences between the two groups. The reflective writings were read by the authors and classified as relevant and irrelevant based on the content being appropriate to the AETCOM module; What it means to be a doctor? The subcategories under each group as boys, girls and anonymous submissions were also analyzed. The variables were expressed in percent. The statistical significance between the two groups was evaluated using unpaired t test. Value of $p$ less than 0.05 was considered as statistically significant.

Qualitative analysis of submitted reflective writings
The contents of the reflective writings were analyzed for the values, attitudes, roles and responsibilities of a doctor as perceived by the students. The authors read the reflective writings and highlighted the text which pertained to the predetermined codes. The authors performed content analysis of the reflective writing submitted, using the predetermined codes based on important attributes of a doctor. The following codes were used for analysis; Professionalism, Empathy, Communication, Ethics, Integrity, Confidentiality, Justice and Commitment. (Bernard HR 2006)

For the purpose of this study, if the text under consideration referred to being rightful/wrongful, just/unjust, it was given the code of "Ethics" (Williams JR, 2015), text referring to appropriate/ inappropriate sending/receiving of information was coded "Communication and when the text referred to emotional cues and responding to them appropriately/inappropriately, it was coded "Empathy" (Hirsch EM, 2007). Similarly, other codes of Integrity, Commitment, Justice and confidentiality were predetermined based on discussion among the authors. The meaningful portions in each narrative were used as excerpts in the results and coded.

\section{Results}

The reflective writings of both the groups were analysed. In the study on group I students, sixty-three students responded out of a total of 149 students whereas 125 students responded among 150 students in Group II who were included for the study.

The results show that the percentage of students who submitted the reflective writing/ narratives were significantly lower in Group I which was a pilot study. The reflective writings submitted were examined for the relevance with respect to the AETCOM module topic. It was found that the percent of relevant reflective writings or narratives were lower at $55.79 \%$ for Group I as compared to $97.6 \%$ for Group II students which was statistically significant. The unpaired t test was applied between the two study groups to study the pattern of responses. The comparative responses of the two study groups and statistical significance is tabulated in table 1 and figure 1. 


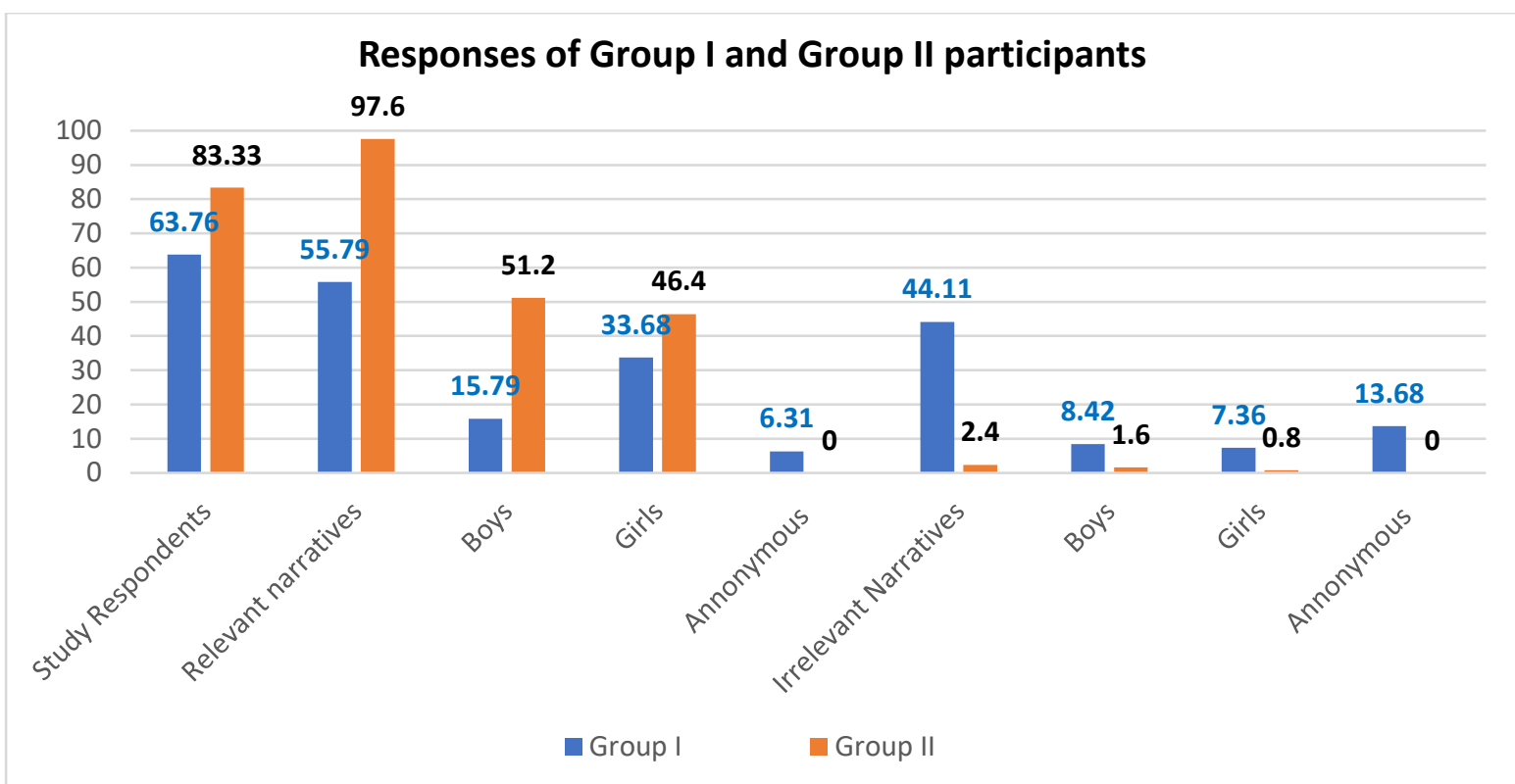

Figure 1: Comparison of responses from Group I and Group II participants in percent Group I; participants of 2017-18 batch first professional year, Group II; participants of 2019-20 batch first professional year.

Table 1: Analysis of student responses to AETCOM module sessions of Group I and Group II participants

\begin{tabular}{|c|c|c|c|c|}
\hline SI. No & Items & $\begin{array}{l}\text { Group I } \\
2017-18\end{array}$ & $\begin{array}{l}\text { Group II } \\
2019-20\end{array}$ & Statistical significance \\
\hline 1. & Study Population & 149 & 150 & \\
\hline 2. & Study Participants/ respondents* & 95 & 125 & \\
\hline 3. & Study participants in percent & 63.76 & 83.33 & $\mathrm{t}=3.831, \mathrm{p}=.0002^{* *}$ \\
\hline 4. & Relevant narratives in percent & $55.79(53)$ & $97.6(122)$ & $t=7.615, p=0000^{* *}$ \\
\hline \multirow[t]{4}{*}{5.} & $\begin{array}{l}\text { Distribution of relevant narratives in percent } \\
\text { Boys }\end{array}$ & & & \\
\hline & Girls & $15.79(15)$ & $51.2(64)$ & $\mathrm{t}=4.385, \mathrm{p}=.0000^{\star *}$ \\
\hline & Anonymous & $33.68(32)$ & $46.4(58)$ & $\mathrm{t}=1.564, \mathrm{p}=.1197$ \\
\hline & & $6.31(6)$ & $0(0)$ & $t=2.801, p=.0057^{* *}$ \\
\hline 6. & Irrelevant narratives in percent & $44.21(42)$ & $2.4(3)$ & $\mathrm{t}=7.613, \mathrm{p}=.0000^{\star *}$ \\
\hline
\end{tabular}




\begin{tabular}{|c|c|c|c|c|}
\hline \multirow[t]{5}{*}{6.} & $\begin{array}{l}\text { Distribution of irrelevant narratives in } \\
\text { percent }\end{array}$ & & & \\
\hline & Boys & $010<0$ & $10(0)+2$ & 1 \\
\hline & Civis & $8.42(8)$ & $1.6(2)$ & $t=2.206, p=.0287$ \\
\hline & & $7.36(7)$ & $0.8(1)$ & $\mathrm{t}=2.423, \mathrm{p}=.0164^{* t}$ \\
\hline & Rाlunymuns & $13.68(13)$ & $0(0)$ & $t=4.173, p=.0000^{* *}$ \\
\hline
\end{tabular}

"Study participants: students who attended all sessions and responded by submitting the reflective writing/ narrative; ${ }^{* *} p$ values which are statistically significant; () values in parentheses are actual numbers.

Among the relevant submissions the subcategories of boys (Group I $15.79 \%$, Group II $51.2 \%$ ) and anonymous responses (Group I $6.31 \%$, Group II $0 \%$ ) were also statistically significant between the two study groups. The percent of irrelevant reflective writings were higher at $44.21 \%$ for Group I as compared to $2.4 \%$ for Group II students which was statistically significant. Among the irrelevant submissions the subcategories of boys (Group | $8.42 \%$, Group || $1.6 \%$ ) girls (Group I $7.36 \%$, Group II $0.8 \%$ ) and anonymous (Group I 13.68 $\%$, Group II $0 \%$ ) responses were found to be significant statistically between the two groups. Results also show that higher percent of anonymous submissions in Group I were irrelevant as compared to submissions which revealed their identity. There was no scope for anonymous submissions in Group II since they recorded the reflections in their respective log books.

\section{Analysis of reflections for codes}

Fifty-three reflective writings from group I and 122 from group II which were found relevant, were analysed qualitatively. The reflective writings/ narratives of both the groups were studied to note the values, attitudes, roles and responsibilities of a doctor as perceived and recorded by the students. using the predetermined codes mentioned in the methods section. The excerpts of student's reflective writings and the codes of group I and II are depicted in table 2 and table 3 respectively. These excerpts show that the students indeed reflected upon the roles and responsibilities of a doctor. Each of the reflections raised multiple attributes corresponding to more than one code (Commitment, ethics, professionalism, communication etc).

Table 2: Excerpts of reflective writing from Group I, first professional students with Codes

\begin{tabular}{|l|l|}
\hline Excerpts & $\begin{array}{l}\text { Codes assigned to excerpts of } \\
\text { submitted reflective writing }\end{array}$ \\
\hline "I understood that 'being humane' is the doctor's most important quality" & Empathy \\
\hline $\begin{array}{l}\text { "I realize that being reachable, impartial and trustworthy are important } \\
\text { qualies of a doctor" }\end{array}$ & Communication, Integrity, Justice \\
\hline "I understand that many people have hopes on us" \\
$\begin{array}{l}\text { "Doctors sacrifice their personal life in the ocean of Medicine to get the } \\
\text { "I want to make my parents and professors proud by being a good doctor in } \\
\text { the society" }\end{array}$ & Commitment \\
\hline $\begin{array}{l}\text { "I got to know the secrets behind the apron, the hard work behind the apron, } \\
\text { the responsibility behind the apron" }\end{array}$ & Professionalism, Commitment \\
\hline "Being a doctor needs a lot of hard work and dedication" & Commitment, Professionalism \\
\hline "The important thing is to gain the trust of the patient" & Professionalism \\
\hline "My only aim and motto from now on is to sacrifice myself for humanity." & Commitment \\
\hline
\end{tabular}




\begin{tabular}{|l|l|}
\hline $\begin{array}{l}\text { "There can be no selfishness in the life of a doctor because he or she is too } \\
\text { busy learning new ways of being able to help the sick even though learning } \\
\text { is a lifelong process." }\end{array}$ & \\
& \\
\hline "A doctor is someone people blindly trust their lives with." & Integrity, Professionalism \\
\hline
\end{tabular}

Table 3: Excerpts of reflective writing from Group II, first professional students with Codes

\begin{tabular}{|l|l|}
\hline Excerpts & $\begin{array}{l}\text { Codes assigned to } \\
\text { excerpts of submitted } \\
\text { reflective writing }\end{array}$ \\
\hline $\begin{array}{l}\text { "As a doctor I understand that I should take responsibility of keeping the society } \\
\text { healthy and free from diseases" }\end{array}$ & $\begin{array}{l}\text { Professionalism, } \\
\text { Commitment }\end{array}$ \\
\hline $\begin{array}{l}\text { "I will always be compassionate, courteous and caring towards the patients and } \\
\text { also respect their autonomy" }\end{array}$ & Empathy, Ethics \\
\hline "What I like about this profession is someone somewhere is always benefitted" & Empathy \\
\hline $\begin{array}{l}\text { "I can't imagine a more fulfilling profession, with great respect comes great } \\
\text { responsibilities" }\end{array}$ & $\begin{array}{l}\text { Professionalism, } \\
\text { Commitment }\end{array}$ \\
\hline $\begin{array}{l}\text { "We as future doctors need to have utmost patience and respect, be punctual and } \\
\text { professional" }\end{array}$ & Professionalism, Empathy \\
\hline $\begin{array}{l}\text { "Doctors have the responsibility to respect confidentiality, to be humble, and he } \\
\text { must give all the information to the patients" }\end{array}$ & Professionalism \\
\hline $\begin{array}{l}\text { "As a doctor I need to imbibe the qualities of a good communicator, a patient } \\
\text { listener, and inculcate ethical values like integrity, accountability, respect and } \\
\text { empathy." }\end{array}$ & $\begin{array}{l}\text { Professionalism, } \\
\text { Communication, Empathy, } \\
\text { Integrity }\end{array}$ \\
\hline $\begin{array}{l}\text { "Doctor's duty includes obligation to diagnose and treat the patient, to understand } \\
\text { patient's expectation, to respect confidentiality, to give information and get } \\
\text { informed consent" }\end{array}$ & $\begin{array}{l}\text { Commitment, Ethics, } \\
\text { Professionalism }\end{array}$ \\
\hline
\end{tabular}

\section{Discussion}

In our pilot study the response rate from group I students of 2017-18 batch was significantly lower as compared to group II, probably because it was not part of their standard curriculum and submission of reflective writing was voluntary. Among the submitted reflective writings we found that only about $55 \%$ were relevant and a huge percent of nearly $45 \%$ were irrelevant. The students had tried to explain their journey of accomplishment in obtaining an MBBS seat, their dreams of getting a medical seat, about the tribulations they encountered during the counselling process and in general used the reflection as a means of telling their stories. Thus, we realized that the students required a platform to express themselves. More importantly we had failed to realise the need to impart to the students the art and purpose of reflective writing in the context of the AETCOM module. The group I participants were self-selected, only the interested and motivated students volunteered to participate in the study. Thus, the results might have been different if we had used random sampling method. The most important learning from the study on Group I was that, it was very important to sensitize the students about the importance of Reflective writing and also train them in the method of reflective writing. The learnings from the study on group I is summarized in Table 4. 
Table 4: Lessons learnt from pilot study on Group I students of 2017-18 batch and suggestions for improvement in the conduct of AETCOM module

\begin{tabular}{|rl|}
\hline 1. & Writing is an art as well as a skill. Not all students have similar abilities and interest in writing \\
\hline 2. & Students come from diverse backgrounds with varying capabilities which needs to be addressed \\
\hline 3. & $\begin{array}{l}\text { The importance Reflective writing in the practice of medicine must be emphasized and demonstrated, } \\
\text { so that the students accept and inculcate it as a process of learning. }\end{array}$ \\
\hline 4. & The technique of narratives and Reflective writing has to be taught and practiced \\
\hline 5. & Methodical reflective writing provides better learning experience for the writer \\
\hline 6. & Anonymous submissions were more likely to be carelessly written/ irrelevant \\
\hline 7. & When submission of narratives was optional, some students opted out and did not benefit. \\
\hline
\end{tabular}

In our subsequent study on Group II students of the 2019-20 CBME batch we found that the response rate was significantly better $(84 \%)$, probably because the submission of reflections was compulsory. But it failed to be hundred percent. The reflective writings were accepted only from those students who had attended and participated in all the scheduled sessions, three sessions for group I and eight for group II under the AETCOM module. We found that about $98.4 \%$ of the reflections that were submitted by group II students were relevant to our AETCOM module objective. This we believe was due to the improvisation done in the conduct of the
AETCOM module by including additional sessions for the Group II students as per $\mathrm{MCl}$ / BOG recommendations and also based on our previous experience. The role plays provided them with experiential learning. Also pertinent was the introduction of the session on Reflective writing to the students, where the knowledge of reflective writing, its importance, benefits and methods of reflective writing were imparted to them. Also, the abilities of the faculty in teaching attitudinal and ethical issues improved with experience. The learnings from the study on group II is summarized in Table 5

Table 5: Lessons learnt from study on Group II students of CBME batch and suggestions for improvement in conduct of AETCOM module

\begin{tabular}{|ll|}
\hline 1. & $\begin{array}{l}\text { It has been observed that teaching of reflective writing skills especially if guided, improved the ability } \\
\text { of students to write reflections and narratives relevant to the learning objectives. }\end{array}$ \\
\hline 2. & Reflective writing promotes student centric learning. \\
\hline 3. & Students can be trained in reflective writing skills. \\
\hline 4. & $\begin{array}{l}\text { Multiplicity of teaching learning modalities improves comprehension and internalization of the } \\
\text { concepts. }\end{array}$ \\
\hline 5. & $\begin{array}{l}\text { The virtues and responsibilities of the doctor were better internalized when the students themselves } \\
\text { participated in the role plays and reflected upon it. }\end{array}$ \\
\hline 6. & The experiential learning substantially improved their understanding. \\
\hline
\end{tabular}

The process of reflection occurs during and after the process of encounter, offering better understanding of the self and the encounter. (Sandars, 2009). Reflective writing engages one in the process of deep understanding and continuous learning. It can improve individual's specific learning situation to have greater selfawareness, professional expertise, critical thinking and resilience. (Jorwekar, 2017)

This also helps the person understand what they already know (individual), identify what they need to know in order to advance understanding of the subject (contextual), make sense of new information and feedback in the context of their own experience (relational) and guide choices for further learning (developmental). (Wald et al., 2009, Wald et al., 2012)

Narratives and reflective writings are important tools for learning attitudinal and ethical issues. It is a metacognitive process that creates greater understanding of self and situations and prepares for an informed future action. (Sandars, 2009) When we analyzed the content of the reflective writings in both our study groups, we found that the students had become aware of the attributes of the doctor. The writings were evidence that the students understood the responsibilities and duties of a doctor, the sacrifices involved in the medical profession and the high stakes involved in treating a patient. A review study found overwhelmingly positive reporting of outcomes 
suggesting that reflective writing should be considered in any medical curriculum. (Chen et al., 2014)

The art of reflective writing among medical students need not be intuitive. They can be trained in this skill early, which is the responsibility of medical educators. The Aronson study reports the benefits of written reflection as an instructional method, as it guides students' critical thinking of their own learning process. (Aronson, 2010).

Reflective writing helps to develop skills that will be needed in future professional life, for dealing with multifaceted problems for which there is no ideal solution. It aids to recognise the importance of being able to frame a problem before trying to solve it. It allows the person, to be able to stand back from himself/herself and question his/her behaviours and attitudes. Medical educators worldwide are examining novel ways to actively train and assess students in professionalism and related competencies. (Singh et al., 2015)

Our findings support the use of reflective narratives, to help medical students learn the importance of being an empathetic clinician, communicator and professional. Successful reflection requires the individuals to recognize the importance of reflection for both personal growth and professional development. Our views were shared by another study which emphasized the need for adopting experiential learning strategies, use of technology in teaching, learning and assessment. (Zayapragassarazan, 2019)

It is genuinely expected that the AETCOM module plays a vital role in providing a coherent picture of how Attitude, Communication and Bioethics can be integrated within medical curriculum and also inspire medical teachers to make it more meaningful and consequential. (Mishra VP, AETCOM 2018)

\section{Conclusion}

Reflective writing and experiential learning are very useful tools for students to acquire the necessary competence in the attitudinal, ethical and communication domains. From the student's perspective reflective writing is a new tool for learning and assessment, hence it is imperative that they should be made aware of its benefits and a systematic process of training for the same should be put in place.

\section{Further Research}

This study could be the basis for future studies that can investigate the influence of reflective writing on medical students' actions in actual practice.

\section{Competing interests and funding support: None declared}

\section{Acknowledgement}

The authors acknowledge the medical education faculty at JNMC, $\mathrm{MCl}$ nodal centre, Belagavi for their inspiration and teachings. They are also extremely grateful to the medical students who willingly volunteered to participate in this project.

\section{References}

Bernard HR, Research methods in anthropology: qualitative and quantitative approaches. 2006 Lanham, MD: AltaMira Press.

Boyd EM and Fales AW, Reflective Learning: Key to Learning from Experience Journal of humanistic psychology, 1983 Volume: 23 issue: 2 : 99-117

Chen I, Forbes C. Reflective writing and its impact on empathy in medical education: systematic review. J Educ Eval Health Prof. 2014; 11: 20.doi:10.3352/jeehp.2014.11.20

Hirsch EM. The role of empathy in medicine: a medical student's perspective. Am Med Assoc J Ethics. 2007;9(6):423-7.

Jorwekar GJ. Reflective practice as a method of learning in medical education: history and review of literature. Int J Res Med Sci 2017; 5:1188-92.

Louise Aronson Twelve tips for teaching reflection at all levels of medical education Medical Teacher 2011;33(3):200-5. doi: 10.3109/0142159X.2010.507714. Epub 2010 Sep 27.

Medical council of India, Competency based undergraduate curriculum for the Indian medical graduate.

https://www.mciindia.org/CMS/informationdesk/for-colleges/ug-curriculum

Medical Council of India. Attitude, ethics \& communication (AETCOM) competencies for the Indian medical graduate. New Delhi: Medical Council of India; https://www.mciindia.org/CMS/wpcontent/uploads/2020/01/AETCOM book.pdf 
Medical Council of India. Vision 2015. Delhi; 2011. Available from: http://www.mciindia.org/tools/announcement/MC booklet.pdf

Mishra VP, Foreword to AETCOM module booklet, Medical council of India.

MQ Patton, How to use qualitative methods in evaluation 1987 Thousand Oaks, CA: Sage.

Novack D H, Epstein R M, Paulsen R H Toward creating physician-healers: fostering medical students' self-awareness, personal growth, and well-being. Acad Med 1999 May;74(5):516-20.

Sandars J, The use of reflection in medical education: AMEE Guide No. 44 Medical Teacher 2009; 31: 685-695

Singh, S., Singh, N., \& Dhaliwal, U. (2015). Promoting competence in undergraduate medical students through the humanities: The ABCDE Paradigm. Research \& Humanities in Medical Education, 2, 28-36. Retrieved from https://www.rhime.in/ojs/index.php/rhime/article/ $\underline{\text { view/16 }}$
Wald, H.S., Borkan, J.M., Taylor, J.S., Anthony, D. \& Reis, S.P. (2012) Fostering and Evaluating Reflective Capacity in Medical Education: Developing the REFLECT Rubric for Assessing Reflective Writing. Academic Medicine, 87, 1, pp.41-50.

Wald, H.S., Davis, S.W., Reis, S.P., Monroe, A.D. \& Borkan, J.M. (2009) Reflecting on Reflections: Enhancement of Medical Education Curriculum with Structured Field Notes and Guided Feedback. Academic Medicine, 84, 7, pp.830837.

Williams JR. Medical Ethics Manual. 3rd ed. FerneyVoltaire Cedex, France: the World Medical Association, Inc; 2015, pp.135);

Zayapragassarazan Z, Kumar S, Kadambari D. Record review of feedback of participants on attitude, ethics and communication module (AETCOM) proposed by Medical Council of India (MCl). Education in Medicine Journal. 2019;11(1):43-48. https://doi.org/10.21315/ eimj2019.11.1.5 